\title{
South Coast REC: Linking urban landscapes, water conservation and water quality
}

D arren Haver, director of South Coast Research and Extension Center (REC), arrives at work without leaving the Irvine suburbs. Passing block after block of housing, old developments and new, he sees irrigation water sheeting off concrete driveways into drains. Reaching the 200-acre REC, which soon will have housing developments right up to the fences, he hears the water running off the driveways of the realistically landscaped housing sites he's had built at the center.

Here, Haver, who also serves as county director and water resources/quality advisor for UC ANR Cooperative Extension (UCCE) in Orange County, is studying two major aspects of residential water use: how much is used in different landscapes, and how much pollution occurs in any runoff from those landscapes.

From $50 \%$ to $70 \%$ of residential water use is applied to landscaping. Typically the landscaping is over-irrigated, producing runoff that enters storm drains and creeks and eventually the ocean. The runoff may contain pesticides, most commonly pyrethroids found in lawn insecticides and ant sprays, which are entering urban watersheds at levels toxic to aquatic invertebrates.

The landscaped housing sites at South Coast REC are testing best management practices (BMPs) for residential water conservation and environmental protection. They serve as demonstration gardens for local homeowners and are inspiring new partnerships beyond UC - with pesticide manufacturers, for example, and even big-box stores.

The residential-use water study began here in this uniquely urban REC in 2005. With environmental chemist Jay Gan, at UC Riverside's (UCR) Department of Environmental Sciences, and entomologists Les Greenberg and Michael Rust, in the UCR Department of Entomology, Haver was investigating how insecticides were reaching local creeks. Haver became interested in the very high use of ant sprays and lawn insecticides around

Researchers at South Coast REC use these three landscaped home sites to study water use and pesticide runoff. From left: Site A, Site B and Site C. homes. "Nobody at that time had a clue about what happens when you apply those sprays to concrete or bricks," recalls Haver - or how much of the chemicals runs off-site.

Three home sites were built at South Coast REC in 2006 to develop, test and implement BMPs for residential landscaping. Each is 40 feet wide by 100 feet long, with a 24-by-24-foot structure, to simulate a home, and a landscaped yard with a standard $2 \%$ slope to the curb.

Site A, the typical landscape site, includes cool-season turf and big-box store plants such as white birch; it has a poorly installed sprinkler irrigation system, and the controller is set to the default position, providing water regularly regardless of weather conditions. A solid concrete driveway funnels roof water and landscape runoff away from the house.

Site B has a low-impact design, sometimes called Mediterranean, used in new housing developments. It has less lawn area, warm-season grass, plants that have some drought tolerance, a better irrigation design with soil moisture sensors, and some permeable flagstone walkway paving and slot drains in the driveway to divert water to planting beds.

Site $C$ is a model of sustainability and water conservation. It has native landscaping, with native Southern California plants, a native sedge lawn, permeable paving and a smart drip irrigation controller that uses weather data from the previous day.

Multiple studies by UC researchers - at the South Coast REC test home sites and elsewhere - have helped to establish the significance of home landscapes as a source of environmental contaminants.

Research undertaken with scientists at the UCR Department of Environmental Sciences (Jiang et al. 2010) showed that pyrethroid insecticides and fipronil (common in ant sprays) are persistent in home landscapes. They were still present in wash-off water 112 days after application to concrete, and for more than 42 days after 14 washing-drying cycles.

At the American Chemical Society National Meeting in 2010, Haver presented, with fellow researchers Tamara Majcherek, from the UC Davis Department of Plant Sciences, and Jay Gan and Sveta Bondarenko, from the UCR Department of Environmental Sciences, the results from an experiment that involved washing down the

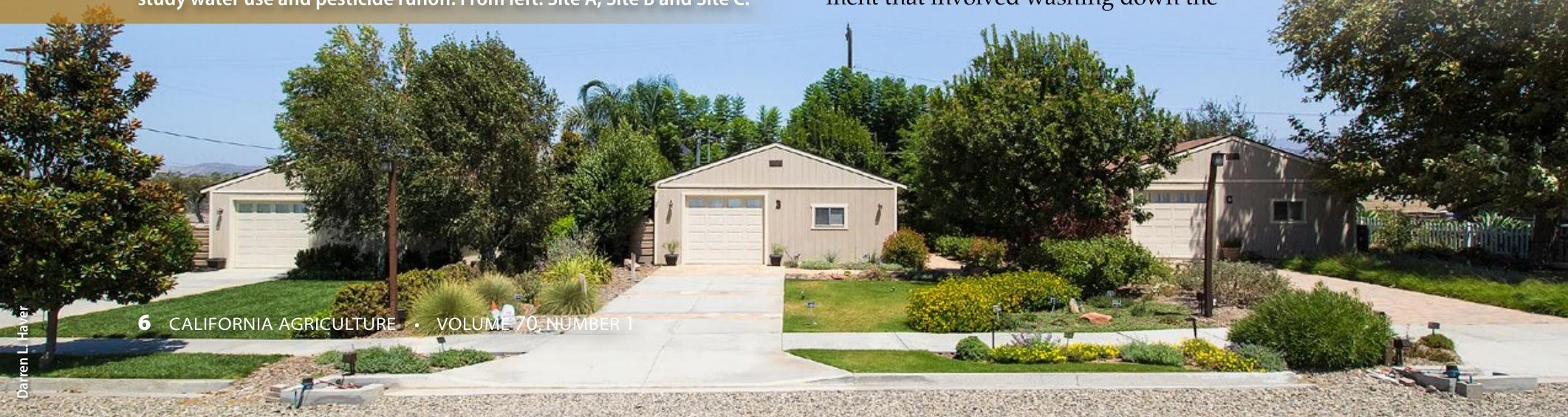



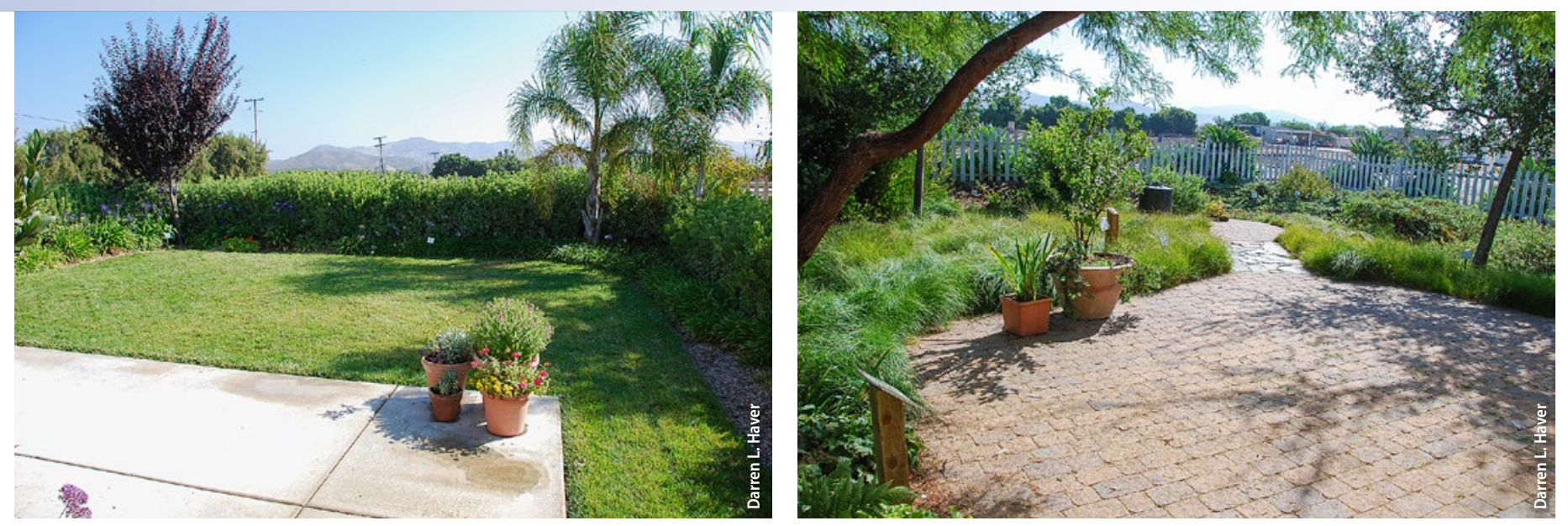

Home site A, left, represents a typical California yard. By contrast, Site C, right, incorporates a variety of features that save water and reduce runoff: native Southern California plants (including the lawn), permeable paving and a smart irrigation controller that responds to weather conditions.

hardscapes after applying common pesticides on the three landscaped sites at South Coast REC (Haver et al. 2010). "People around here don't like their driveways dirty," says Haver, about the frequent hosing of hardscapes in the suburbs. Washing off the hardscape within 24 hours of the applications resulted in a significant amount of bifenthrin and fipronil running off from all three sites. But the fipronil load was 32 times greater from Site A, the typical site with concrete hardscaping, than from Site C, and the bifenthrin load was five times greater from Site A.

Haver works at UCCE because he's a problem solver. "I like to help homeowners sort out water quality issues," he says. The challenge in the residential water-use project is how to best effect change among homeowners, how to get the BMPs adopted in residential communities.

The answer may be a matter of regulation or urban planning. Haver collaborated with Lorence Oki at the UC Davis Department of Plant Sciences on a multiyear study of residential runoff in Sacramento and Orange counties, and the water flow data they collected is helping UC Davis Department of Environmental Design scientists perform pollutant load modeling for urban areas before and after implementing BMPs. The modeling will be useful for policymakers and planners.

In the absence of regulation, changing homeowners' behavior is a formidable challenge. Science has provided the data, but few homeowners are switching to warm-season turfgrass or smart irrigation controllers, two of the simplest, least expensive BMPs. So Haver has expanded the project to look at people's behavior.

Thousands of local homeowners have visited the three landscaped sites at the REC's public events. In 2012, Haver, in collaboration with Lillian Hayden, Mary Cadenasso and Lorence Oki in the Department of Plant Sciences at UC Davis, surveyed the visitors regarding their preferences at an event focused on water conservation BMPs.

The surveys revealed an aesthetic preference $(60 \%$ of respondents) for Site B, the low-impact, or Mediterranean, landscape (Hayden et al. 2015) even while the respondents recognized that Site $C$ was the least expensive to maintain and the most conserving of water. The researchers concluded that landscaping practices might not be the best area in which to try to achieve residential water conservation, unless homeowners' aesthetics could be changed or the water-conserving landscapes be made more appealing to homeowners.

In terms of changing homeowners' landscape choices and practices, Haver says "we have a long ways to go." Fewer than $7 \%$ of visitors completing a survey at the fall 2015 open house reported they had implemented a BMP. Public education will continue to be a major part of the project at the REC; Haver hopes the sites will be made open year-round to the public, so people are inspired by the professionally designed but "very doable" water-friendly landscaping and can learn how easy the BMPs are to implement.

There's strong interest in shaping new consumer practices among the change agents and tastemakers Haver has gathered around this project to improve residential water use. Outreach to and partnerships with garden maintenance companies, pesticide application companies, landscape architects, irrigation supply companies, housing contractors and developers and even pesticide manufacturers have been established. Many of those partners have their own data on consumer

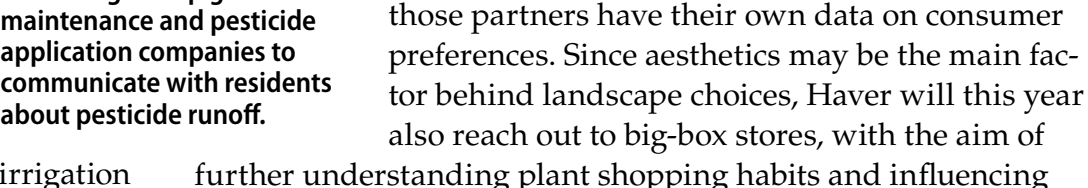
$\begin{array}{ll}\begin{array}{l}\text { maintenance and pesticide } \\ \text { application companies to } \\ \text { communicate with residents } \\ \text { about pesticide runoff. }\end{array} & \begin{array}{l}\text { those partners have their own data on consumer } \\ \text { tor behind landscape choices, Haver will this year } \\ \text { also reach out to big-box stores, with the aim of }\end{array} \\ & \text { further understanding plant shopping habits and influencing }\end{array}$ $\begin{array}{ll}\begin{array}{l}\text { maintenance and pesticide } \\ \text { application companies to } \\ \text { communicate with residents } \\ \text { about pesticide runoff. }\end{array} & \begin{array}{l}\text { those partners have their own data on consumer } \\ \text { tor behind landscape choices, Haver will this year } \\ \text { also reach out to big-box stores, with the aim of }\end{array} \\ \text { irrigation further understanding plant shopping habits and influencing }\end{array}$ further understanding plant shopping habits and influencing
the selection of water-conserving plants the stores sell. CA -Hazel White

\section{References}

Haver DL, MajcherekT, Bondarenko S, Gan J. 2010. Pesticide detections in washoff from residential hardscapes generated at defined intervals. In: Proc of 239th Amer Chem Soc (ACS) Nat Mtg and Expo, Mar. 21-25, 2010. San Francisco, CA. Abstract 298.

Hayden L, Cadenasso ML, Haver D, Oki L. 2015. Residential landscape aesthetics and water conservation best management practices: Homeowner perceptions and preferences. Landscape Urban Plan 144:1-9.

Jiang W, Lin K, Haver D, et al. 2010. Wash-off potential of urban use insecticides on concrete surfaces. Environ Toxicol Chem 29(6):1203-8. 